\title{
Observations of the 16-day wave in the equatorial meteor winds and TIMED/SABER temperatures
}

\author{
Lourivaldo Mota Lima DF/UEPB, Brazil \\ Joaquim Fechine, Hisao Takahashi, P. P. Batista, INPE, Brazil \\ Cristiano Max Wrasse IP\&D/UNIVAP, Brazil \\ G. Mlynczak, NASA Langley Research Center, Hampton, VA, USA \\ J. M. Russell Hampton University, Hampton, VA, USA
}

Copyright 2007, SBGf - Sociedade Brasileira de Geofísica

This paper was prepared for presentation at the $10^{\text {th }}$ International Congress of The Brazilian Geophysical Society held in Rio de Janeiro, Brazil, 19-22 November 2007.

Contents of this paper were reviewed by the Technical Committee of the $10^{\text {th }}$ International Congress of the Brazilian Geophysical Society and do not necessarily represent any position of the SBGf, its officers or members. Electronic reproduction, or storage of any part of this paper for commercial purposes without the written consent of the Brazilian Geophysical Society is prohibited.

\begin{abstract}
Horizontal wind measurements obtained from São João do Cariri-PB $\left(7.4^{\circ} \mathrm{S}, 36.5^{\circ} \mathrm{W}\right)$, Brazil, associated with equatorial MLT temperature data acquired by the TIMED/SABER satellite, have been used to investigate the presence of planetary-scale oscillations. The data were obtained from January to December, 2005, which were subjected to the spectral analysis and the results revealed the quasisimultaneous presence of distinct power spectrum with peaks associated with low-frequency oscillations. In this time, our focus is the range period from 12 to 20 days, whose activities were revealed mainly during time-intervals from day 120 to day 250 . The characteristics observed suggest that the perturbations were due to presence of 16-day planetary waves. From satellite data, was possible identified a westward propagating 16-day wave with zonal wave number 1 .
\end{abstract}

\section{Introduction}

The middle and upper atmosphere is a region highly active and their global circulation hold wave motions that drive the departure from radiative equilibrium. Modeling studies have predicted a cooling in stratopause and mesopause temperatures in response to increases of greenhouse gas concentrations. In this way, it is necessary to study the relationship among parameters in the middle atmosphere to contribute to our understanding of global atmospheric changes.

The dynamical structure of the mesosphere and lower thermosphere $(\mathrm{MLT})$ region depends on solar energy and on the momentum sources provided by atmospheric waves that ascend from lower atmosphere into the MLT region, which are considered the major MLT dynamical forcing. Atmospheric waves with period raging from 2 days to 30 days have been observed either wind or temperature fields and are generally referred to as planetary waves. Theoretical studies and numerical models have indicated that vertical propagation is permitted under suitable conditions (Beer, 1975; Holton, 1992).

In the MLT region the planetary waves are commonly observed with periods that fall around 2 days, 5-7 days, 8-10 days and 12-22 days. Usually, we compare these waves with asymmetric mixed Rossbygravity $(s=3, n=-3)$ mode, first symmetric Rossby (1, $2)$ mode, first asymmetric Rossby $(1,-3)$ mode and second symmetric Rossby $(1,-4)$ mode, respectively, which are described by Laplace's tidal equation. Here, $s$ denotes the zonal wavenumber and $n$ is the meridional index derived from the subscripts of Hough functions (Forbes, 2000).

Winds and temperatures in the middle atmosphere are measured from the ground-based instruments (radars, lidars, and optical interferometers) and from satellite-borne systems. The ground-based instruments usually provided a high time resolution, but are poorly distributed over the globe, whilst the satellite observations offer a global coverage, but the time resolution are limited by orbit to fixed points on the globe.

16-day wave are oscillations with periods between 12 and 20 days. This wave is a westward propagating zonal wavenumber one $(s=1)$ oscillation, and has been identified as the second symmetric Rossby (1,4) mode.

Williams and Avery (1992) measured oscillations with periods between 12 and 19 days at Poker Flat $\left(65^{\circ} \mathrm{N}\right.$, $147^{\circ} \mathrm{W}$ ), Alaska, from MST (mesospherestratosphere-troposphere) radar data obtained during 1984. Espy et al. (1997) identified 16-day wave signatures in the mesopause temperatures at Stockholm $\left(60^{\circ} \mathrm{N}\right)$, Sweden during 1992 and 1994 summers, but not in the summers of 1993 and 1995 just during eastward phase years of the equatorial quasi-biennial oscillation (QBO) in the upper stratosphere. MLT region climatological studies of the 16-day oscillations for the northern hemisphere reveal that the strongest activity occurs during winter solstices (January-March), which is believed to be the result of vertical propagation from lower levels (Forbes et al., 1995; Luo et al., 2002). Lima et al. (2005) reported climatological and structure features of the 16-day wave observed with meteor radar at $22.7^{\circ} \mathrm{S}$ 
Numerical simulations of the 16-day wave under January conditions were performed by Forbes et al. (1995), and confirmed the interpretation that this wave is a result of direct upward propagation into the $M L T$ region. The simulations also suggested some leakage of these waves across the equator and into the summer mesopause region. Miyoshi (1999) used a general circulation model to examine the behavior of the 16-day wave in the MLT region, and found that the inter-hemispheric penetration of the 16-day wave occurs near the mesopause region.

In this study we examine the 16-day wave characteristics using meteor wind and satellite temperature observations for equatorial sector.

\section{Observations}

The wind data used in this study were obtained from meteor radar installed at São João do Cariri $\left(7.4^{\circ} \mathrm{S}\right.$, $\left.36.5^{\circ} \mathrm{W}\right)$, Brazil, during 2005 year. The All-sky SKiYMET Meteor Radar operates at a VHF frequency of $35.24 \mathrm{MHz}$ with a peak power of $12 \mathrm{~kW}$ and a pulse repetition frequency of $2144 \mathrm{~Hz}$. It uses a single 3element Yagi transmitting antenna and 5-channel interferometer Yagi receiving antennas, which are arranged in the form of an asymmetric cross. Meteor position is obtained from the relative phase of the echoes at the multiple antennas together with the echo range. Radial velocity is determined from the Doppler shift. Typically the Cariri radar detects about 5000 echoes per day making it possible to determine winds with a time resolution of one hour and a height resolution of $3 \mathrm{~km}$ from 80 up to $100 \mathrm{~km}$.

For 16-day wave analysis, we used daily-mean wind data, which were obtained from the winds estimated in 1-hour time bins and in seven height intervals of 4 $\mathrm{km}$ thickness each, centered in the $81,84,87,90,93$, 96 , and $99 \mathrm{~km}$ altitudes, with a height overlap of 0.5 $\mathrm{km}$, assuming a uniform and constant wind for each height/time bin.

Temperature data used in the present study were obtained by Sounding of the Atmosphere by Broadband Emission Radiometer (SABER) instrument, which is onboard of the Thermospherelonosphere-Mesosphere Energetics and Dynamics (TIMED) satellite. The SABER instrument is an infrared radiometer with 10 channels ranging from $1.27 \mu \mathrm{m}$ to $16 \mu \mathrm{m}$. It derived the vertical profiles of kinetic temperature from limb observations of $\mathrm{CO}_{2}$ emissions with precision of $3 \mathrm{~K}$ below $100 \mathrm{~km}$ (Mertens et al., 2001). In this study the level $2 \mathrm{~A}$ kinetic temperature data from 50 to $100 \mathrm{~km}$, are used.

\section{Results}

As the planetary wave activities display nonstationary characteristics, we used a method able to detect and to identify signals with transient information content or non-stationary properties. One method of analysis of non-stationary wind fluctuations is the wavelet transform, which has become a common tool for analyzing localized variations of power within a time series (Torrence and Compo, 1998).

The power spectra for zonal wind calculated from Morlet wavelet transform, for altitudes $84 \mathrm{~km}$ (bottom), $90 \mathrm{~km}$ (middle) and $96 \mathrm{~km}$ (upper), are presented in Figure 1.

From this figure, the presence of oscillations whose periods can be associated with planetary waves is apparent in the zonal winds. Spectral energy associated with 16-day planetary wave can be identified during time interval from day 120 to day 240, mainly for $90 \mathrm{~km}$ and $96 \mathrm{~km}$ spectrum results.
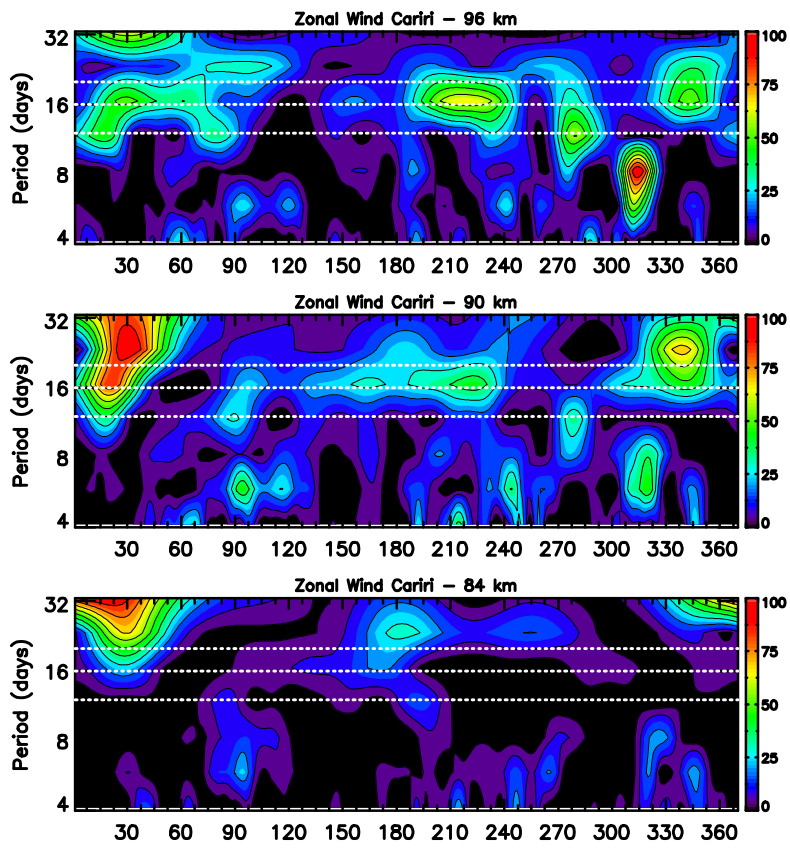

Fig. 1. Morlet wavelet transform spectrum results for the zonal daily mean winds at $96 \mathrm{~km}$ (top), $90 \mathrm{~km}$ (middle) and $84 \mathrm{~km}$ (bottom) observed during 2005 over Cachoeira Paulista-Brazil. A Morlet wavelet mother was applied. The gray-level indicates the normalized spectral power and the dotted lines indicate the 12-20 day period range centered in 16 day.

To verify the behavior of the 16-day oscillation in the time domain we have applied a filter with a band pass of 12-20 days to the time series of the zonal winds for all 7 height intervals.

Figure 2 shows bandpass filtered winds for the zonal component observed at seven altitudes during the 2005 year. We can see 16-day amplification events, mainly for height above $87 \mathrm{~km}$. As can be see from Figure 2, the 16-day oscillation persists at almost all times, for heights above $87 \mathrm{~km}$. 


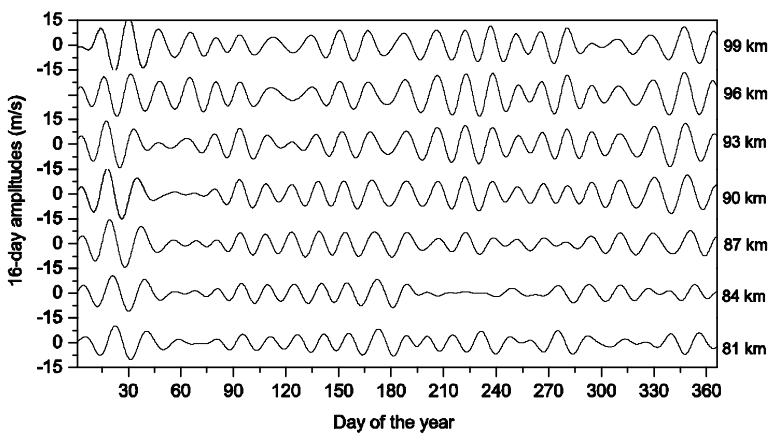

Fig. 2. Filtered time series for zonal component of the winds at seven altitude levels over São João do Cariri. The data were filtered by a bandpass filter with cutoff periods of 12 and 20 days.

To study temperature modulation by 16-day wave, we consider the time interval from day 120 to day 250 . Hence, we have also applied a filter with the same characteristics (bandpass of 12-20 days) to the time series of the temperature obtained by SABER instrument for 4 height intervals. The 16-day filtered temperature can be seen in the Figure 3 for time interval from day 120 to day 250 . From this figure, it is possible to observe 16-day amplification for temperature, which are consistent with zonal wind data.

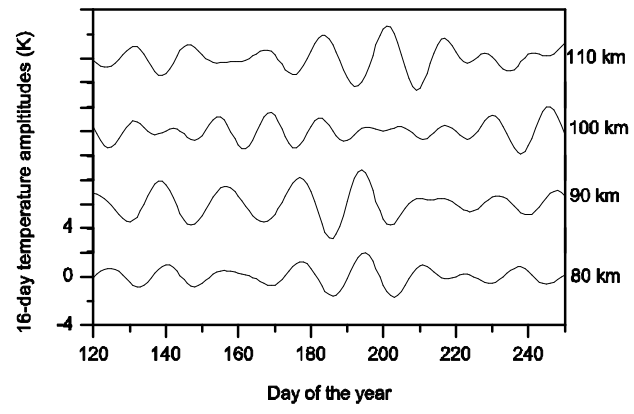

Fig. 3. Filtered time series for 16-day filtered temperature obtained by SABER instrument for 4 height intervals. The data were filtered by a bandpass filter with cutoff periods of 12 and 20 days.

Figure 4 shows the 12- to 20-day filtered temperature data at altitudes of $70 \mathrm{~km}$ (bottom panel), $85 \mathrm{~km}$ (middle panel) and $95 \mathrm{~km}$ (upper panel) over longitude band of $2^{\circ} \mathrm{S}$ to $12^{\circ} \mathrm{S}$ for the time interval from day 120 to day 240, 2005.

In this figure we can see the global feature of the 16-day oscillation. Additionally, it is possible to observe that the 16-day oscillation appears to be more active for $95 \mathrm{~km}$ height with maximum amplitudes reaching $\sim 7 \mathrm{~K}$.

The time-longitude structure for altitude of $85 \mathrm{~km}$ suggest that the wave takes nearly 16 days to propagate from east to west around latitude circle, indicating a zonal wave number of 1 , which is compatible with second symmetric Rossby mode.
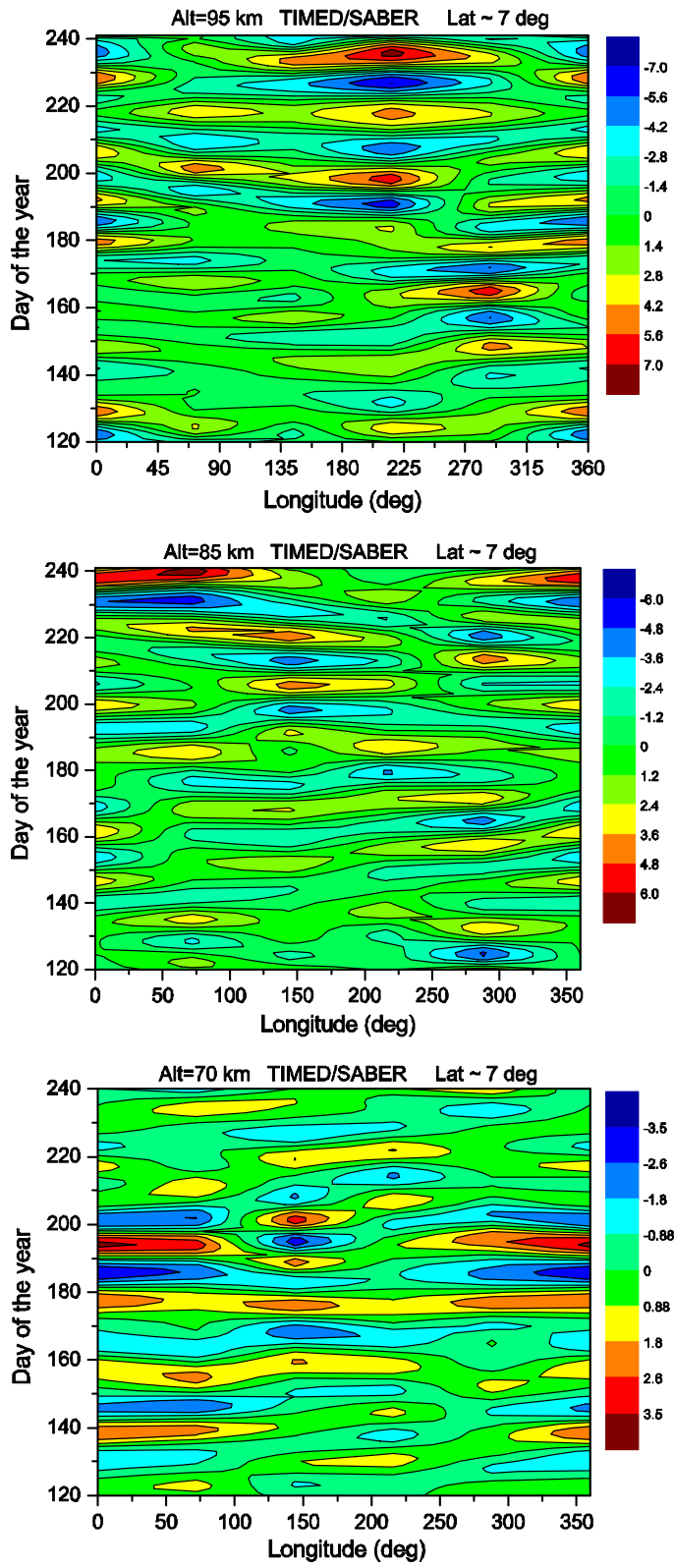

Figure 4 - Time-Longitude cross-section of 12- 20-day bandpass filtered temperature at $70 \mathrm{~km}$ (bottom panel), $85 \mathrm{~km}$ (middle panel) and $95 \mathrm{~km}$ (upper panel). The temperature are obtained by SABER aboard TIMED satellite.

\section{Conclusions}

Measurements of meteor winds, obtained at São João do Cariri, and of temperature, obtained by SABER instrument aboard of the TIMED satellite, during 2005 year, were used to investigate 16-day oscillations at equatorial region. 
Our results indicated that MLT temperatures obtained by SABER/TIMED are modulated by 16-day oscillations, which also are observed in the zonal winds obtained by meteor radar over São João do Cariri.

The global feature of the 16-day oscillation, from satellite data, shows a time-longitude structure compatible with a westward propagating 16-day wave with zonal wave number one.

\section{Acknowledgments}

The present work was partially supported by the Conselho Nacional de Desenvolvimento Científico e Tecnológico, CNPq, the Fundação de Apoio à Pesquisa do Estado de São Paulo, FAPESP. We are also grateful to the Observatório de Luminescência Atmosférica da Paraíba - OLAP, UFCG.

\section{References}

Beer, T. Atmospheric Wave. London: Adam Hilger, 1975.

Espy, P. J.; Stegman, J.; Witt, G. Interannual variations of the quasi-16-day oscillation in the polar summer mesospheric temperature. Journal of Geophysical Research, v. 102, n. D2, p. 1983-1990, 1997.

Forbes, J. M. Wave coupling between the lower and upper atmosphere: case study of an ultra-fast Kelvin wave. Journal of Atmospheric and Terrestrial Physics. v. 62 , n. 17-18, p. 1603-1621, 2000.

Forbes, J. M.; Hagan, M; Miyahara, S.; Vial, F.; Manson, A. H.; Meek, C. E.; Portnyagin, Y. I. Quasi 16-day oscillation in the mesosphere and lower thermosphere. Journal of Geophysical Research, v. 100, n. D5, p. 9149-9163, 1995.

Holton, J. R. An Introduction to Dynamic Meteorology 3 ed. San Diego: Academic Express, 1992.

Lima, L. M.; Batista, P. P.; Clemesha, B. R.; Takahashi, H. 16-day Waves Observed in the Meteor Winds at Low Latitudes in the Southern Hemisphere. Advances in Space Research, v. 38, n. 11, p. 2615-2620, doi:10.1016/j.asr.2006.03.0332006.

Luo, Y.; Manson, A. H.; Meek, C. E.; Meyer, C. K.; Burrage, M. D.; Fritts, D. C.; Hall, C. M.; Hocking, W. K.; MacDougall, J.; Riggin, D. M.; Vincent, R. A. The 16-day planetary waves: multi-MF radar observations from the arctic to equator and comparisons with the HRDI measurements and the GSWM modelling results. Annales Geophysicae, v. 20, n. 5, p. 691-709, 2002.

Mertens, C. J.; Mlynczak, M. G.; Lópes-Puertas, M.; Wintersteiner, P. P.; Picard, R. H.; Winick, J. R.; Gordley, L. L.; Russell, J. M. Retrieval of mesospheric and lower thermospheric kinetic temperature from measurements of $\mathrm{CO}_{2} 15 \mu \mathrm{m}$ Earth limb emission under non-LTE conditions. Geophysical Research Letters, v. 28, n. 7, p. 13911394, 2001.
Miyoshi, Y. Numerical simulation of the 5-day and 16-day waves in the mesopause region. Earth, Planets and Space, v. 51, n. 7-8, p. 763-784, 1999.

Torrence, C.; Compo, G. P. A practical guide to wavelet analysis. Bulletin of the American Meteorological Society, v. 79, n. 1, p. 61-78, 1998.

Williams, C. R.; Avery, S. K. Analysis of long-period waves using the mesosphere-stratosphere-troposphere radar at Poker Flat, Alaska. Journal of Geophysical Research, v. 97, n. D18, p. 855-861, 1992. 